\title{
Effect of Web Openings on Flexural Behaviour of Underground Metro Station RC Beams under Static and Cyclic Loading
}

\author{
Ting-jin Liu $\mathbb{D}^{1,2,3,4}$ Si-wei Chen, ${ }^{3}$ Zi-hang Feng, ${ }^{3}$ and Hong-yuan Liu ${ }^{4}{ }^{4}$ \\ ${ }^{1}$ State Key Laboratory of Subtropical Building Science, South China University of Technology, Guangzhou 510640, \\ Guangdong, China \\ ${ }^{2}$ South China Institute of Geotechnical Engineering, South China University of Technology, Guangzhou 510640, \\ Guangdong, China \\ ${ }^{3}$ School of Civil Engineering and Transportation, South China University of Technology, Guangzhou 510640, Guangdong, China \\ ${ }^{4}$ School of Engineering, University of Tasmania, Hobart 7005, Tasmania, Australia
}

Correspondence should be addressed to Ting-jin Liu; liu_tingjin@163.com

Received 8 November 2019; Revised 13 January 2020; Accepted 20 January 2020; Published 17 February 2020

Academic Editor: Eric M. Lui

Copyright (c) 2020 Ting-jin Liu et al. This is an open access article distributed under the Creative Commons Attribution License, which permits unrestricted use, distribution, and reproduction in any medium, provided the original work is properly cited.

This paper investigates the influence of multiple transverse web openings on the flexural behaviour of underground metro station reinforced concrete (RC) beams. This problem is outlined with an actual underground engineering project, in which the web opening used in the RC beams violates the current specifications. A total of five beams with different numbers of web openings are fabricated and tested under static and cyclic loading conditions, thereby simulating actual operations in unfavourable conditions. The results suggest that the existence of the openings decreases the loadbearing capacity, ductility, stiffness, and energy dissipation ability of the RC beams. Moreover, the results show that the corners of the openings are the weakest parts of the beams. However, additional reinforcements around the openings can partially mitigate the impact of the openings on the loadbearing and seismic performance of the RC beams. The laboratory experiments presented herein not only provide guidelines for the use of RC beams with web openings in actual engineering projects, especially underground projects where RC beams with web openings have seldom been investigated, but also shed light on improving the related design specifications.

\section{Introduction}

In metro stations, a certain amount of space in the ceiling, the so-called dead space, is required for the passage of pipes and ducts for air-conditioning, heating, sewage, and water supply systems. The utilization of this dead space reduces the heights of the loadbearing and nonloadbearing members and subsequently the net height of the station. Therefore, for a more efficient and economical design of subway stations, openings are frequently placed in the web area of the top beams to facilitate essential services or even personal movement from one room to another. However, the inclusion of web openings in reinforced concrete (RC) beams will reduce their loadbearing capacity. By deploying additional reinforcements, an RC beam with web openings can be applied in practice and provide a loadbearing capacity and stiffness close to those of a solid beam with the same dimensions. The installed reinforcements should also counteract the negative effects of the stress concentrations around the openings and prevent the premature failure of the RC beam. Numerous experimental and analytical studies have been conducted to investigate the mechanical properties of flexural RC beams with openings.

As examples, the Japanese specification [1] presents a method for obtaining the loadbearing capacity of beams with small circular holes. The American Concrete Institute (ACI) [2] enriches the calculation theory for beams with T-section openings, which treats the upper and lower chords as compressive and tensile rods, respectively. The Canadian Code [3] proposes a model for the tensile and compressive rods to obtain the loadbearing capacity, but many variables in the model are not given quantitatively. 
Ashour and Rishi [4] conducted 16 experiments on twospan continuous deep RC beams with web openings. The web openings were arranged in different shapes and locations to study the resulting effects. They found that vertical reinforcements beside the web openings were more beneficial to the loadbearing capacity of the beam than horizontal reinforcements. Tsavdaridis et al. [5] performed a comprehensive finite element (FE) analysis to study the mechanical performance of perforated steel sections (four different sizes) containing 11 different standard and novel nonstandard web openings (3 different sizes). The web opening was located in different positions to study the Vierendeel mechanism. They revealed the effect of the shape and the location of the web opening along the length of the perforated beam on its structural behaviour. Campione and Minafò [6] tested the flexural behaviour of twenty smallscale deep RC beams with or without openings under fourpoint bending tests. They concluded that the failure mode and first cracking load were mainly dependent on the presence and different positions of the openings. Aykac et al. [7] conducted experiments on a total of nine rectangular beams with various openings uniformly distributed along the beam span. They concluded that diagonal reinforcements around the openings effectively prevented premature failure due to the Vierendeel action. Mohamed et al. [8] utilized the finite element method to study the behaviour of deep RC beams with and without web openings. The web openings were placed in both the pure flexure zone and the flexure-shear zone in different specimens. They suggested that web openings crossing the expected compression struts should be avoided, and the depth of the opening should not exceed $20 \%$ of the beam overall depth. Morkhade and Gupta [9] and their team [10-12] investigated the strength values, ultimate loadbearing capacities, and failure behaviours of a series of steel beams with web openings of different shapes using analytical, experimental, and numerical methods. The web openings were symmetrically distributed along the beam span, and the whole beam was subjected to a single concentrated load applied at the centre of the span. They summarized that the rectangular openings on the beams were very critical, as very high stresses were concentrated around the corner regions. The height-to-thickness ratio was found to be the main parameter influencing the buckling behaviour of steel beams with web openings. Additional stiffeners should be provided to enable a better stress redistribution in the beams with web openings. Almusallam et al. [13] studied the behaviour of fibre-reinforced polymerstrengthened RC beams with web openings in the flexure zone. They concluded that for RC beams with openings in the pure flexure zone and with a top chord depth less than that of the concrete stress block, an additional strengthening method should be adopted for better performance. Furthermore, for RC beams with web openings located in the zone with high flexure and high shear, the strengthening effectiveness depended on the relationships between the length of the openings and the depths of the top and bottom chords. Based on the strong column/weak beam design hierarchy, Nie et al. [14] proposed a novel seismic retrofitting method and utilized local fibre-reinforced polymer
(FRP) strengthening to avoid shear failure in a weakened T-section beam with openings, thereby ensuring a ductile failure process. Their results showed that the FRP strengthening system was rather effective in avoiding shear failure and confining the web chords. In addition to partial reinforcing methods, other scholars [15-17] investigated additional strengthening methods to compensate for the effect of web openings.

Many researchers have studied the seismic behaviour of structural components [18-20]. Herrera et al. [21] carried out a large-scale experimental study to investigate the cyclic behaviour of T-shaped moment-resisting frame (MRF) cantilever beams with openings placed in the midspan. They concluded that both strong shear reinforcement around the opening and continuous chord reinforcement were crucial for beams with openings to retain full structural integrity. No other published material on RC beams with web openings under cyclic loads has been identified by the authors.

In summary, the literature reviewed in the introduction section focused on investigating and improving the mechanical properties of RC beams with openings so that these members can satisfy the requirements of aboveground structures. There were few studies that mainly focused on the mechanical behaviour of underground metro station RC beams with openings, which are normally subjected to much greater loads and designed according to stricter requirements than aboveground structures. In this paper, underground metro station RC beams with openings are first designed to satisfy the requirements of metro stations; the opening areas in these $\mathrm{RC}$ beams must be larger than those in aboveground structures to enable more essential services in limited underground spaces. Moreover, the design of these underground metro station $\mathrm{RC}$ beams with large openings violates the current Chinese specifications [22]. Correspondingly, after implementing a scale factor of 2.5, a total of five scaled RC beams with a span length of $3,460 \mathrm{~mm}$ are fabricated and tested under static and cyclic loading conditions to investigate their flexural behaviours in the most unfavourable conditions encountered in practical underground engineering applications. Afterwards, the ductility, rigidity, hysteresis characteristics, and energy dissipation ability of the RC beams with different openings under different loading patterns are discussed. It is hoped that the experimental results in this paper can help develop guidelines for designing underground metro station RC beams with web openings and guide actual engineering construction and specification optimization.

\section{Violation of Design Specifications}

Since the RC beams with openings were designed to facilitate more services and satisfy underground metro station requirements, a larger area opening was deployed, which violates the current design specifications [22], as summarized in Table 1. For the specimens with only one opening, the eccentricity of the opening to the tension zone (i.e., the 
TABLE 1: Violated specifications (mm).

\begin{tabular}{|c|c|c|c|}
\hline Specimens & Requirements & Design* & Recommended limit \\
\hline Beam O & $\begin{array}{l}\text { Eccentricity of the opening to the tension zone } \\
\text { Net distance between adjacent openings }\end{array}$ & $\begin{array}{l}70 \\
-\end{array}$ & $\leq 34$ \\
\hline Beam $\mathrm{T}$ & $\begin{array}{l}\text { Eccentricity of the opening to the tension zone } \\
\text { Net distance between adjacent openings }\end{array}$ & $\begin{array}{c}10 \\
240\end{array}$ & $\begin{array}{l}\leq 38 \\
\geq 950\end{array}$ \\
\hline
\end{tabular}

*Values of the scaled specimens are used in Table 1.

distance between the middle line of the beam height to the middle line of the opening height: $70 \mathrm{~mm}$ ) is twice the recommended upper limit ( $5 \%$ of the beam height: $34 \mathrm{~mm}$ ). For the specimens with three openings, the net distance between the adjacent openings $(240 \mathrm{~mm})$ is only $25.3 \%$ of the recommended lower limit (2.5 times the opening height: $950 \mathrm{~mm})$.

\section{Experimental Testing Method}

As a hub site for metro transportation, metro stations not only serve as passenger bridges connecting the ground and underground but also function as passenger transferring media between different lines. Thus, the safety and stability of metro stations are paramount. With the development of underground transportation, prefabricated metro stations are gradually being adopted in mainland China. Compared to aboveground structures, more space is required for facilitating essential services in a metro station. To reduce the utilization of the station ceiling space, the so-called dead space, engineers have started to analyse the feasibility of creating larger web openings on the top RC beams of the metro station; however, the design of these beams violates the current specifications. Accordingly, beams with larger web openings should be experimentally tested before being adopted in engineering practice.

As shown in Table 2 and Figures 1-3, a total of five RC beams with a span length of $3,460 \mathrm{~mm}$ were fabricated and tested. The specimen with a $400 \mathrm{~mm} \times 680 \mathrm{~mm}$ rectangular section without openings was denoted with the capital letter " $R$ " (i.e., the reference beam). Two specimens with $400 \mathrm{~mm} \times 680 \mathrm{~mm}$ rectangular sections were denoted with the capital letter "O," in which each has one $840 \mathrm{~mm} \times 220 \mathrm{~mm}$ rectangular opening. Two specimens with $400 \mathrm{~mm} \times 760 \mathrm{~mm}$ rectangular sections were denoted with the capital letter " $\mathrm{T}$," in which each has two $760 \mathrm{~mm} \times 380 \mathrm{~mm}$ rectangular openings and one $580 \mathrm{~mm} \times 380 \mathrm{~mm}$ rectangular opening. Both the locations and the sizes of the web openings were designed to meet the needs in engineering practice. The reinforcements used in the specimens can be divided into 4 different groups: side reinforcements, chord reinforcements, diagonal reinforcements, and stirrup reinforcements, as detailed in Table 2 and Figures 1-3.

3.1. Reinforcement Arrangement. As illustrated in Figures 2-3, the diagonal reinforcements were used to control the crack widths. Moreover, the upper and lower chord reinforcements were adopted in the beams with openings to improve local stiffness around the openings to prevent brittle failure.

The beams were cast in three different batches of concrete. Three $150 \times 150 \times 150 \mathrm{~mm}^{3}$ concrete cubes were cast for each concrete batch, and the compressive strength of these cubes was tested on the $28^{\text {th }}$ day of curing. The average compressive strength values obtained from these tests are tabulated in Table 2. Three reinforcing bars of each size were tested to obtain the average yield strength. The average yield strength values of the $\Phi 12,10$, and 6 bars were measured as 439.5 $\mathrm{MPa}$, 432.7 MPa, and 440.2 $\mathrm{MPa}$, respectively.

3.2. Experimental Setup of the Static and Cyclic Loading Tests. A schematic of the testing setup is provided in Figure 4, which shows that the specimens were simply supported on two steel-concrete supports and loaded in a steel frame with a loading capacity of $4000 \mathrm{kN}$. For the static loading tests, the beams were cast with $400 \mathrm{~mm}$-long extended ends and contained both side reinforcements and stirrup reinforcements. The extended ends on both sides were used to simulate the reverse bending moment on continuous beams. The loads from eight JT hydraulic cylinders were equally distributed on the test beams. Two JE hydraulic cylinders were positioned on both extended ends to exert negative moments on the test beams. The settlement of the two supports and the vertical deflections at the midspan were collected through five linear variable differential transformers (LVDTs).

Special attention was paid to achieving equal and concentric loading on the test beams with the JT hydraulic cylinders. The deviations from this uniform loading due to the excessive asymmetrical deformations in the plastic phases of the tests were ignorable. The beams were loaded up to designed levels to simulate the conditions in actual engineering projects. For static loading, the loads from hydraulic cylinders JE1 and JE2 were 3.3 times and 2 times larger than that from the JT hydraulic cylinders, respectively. The locations and widths of the cracks generated at different load levels were marked and measured, respectively. Each specimen was instrumented with an extensive set of internal sensors. A large number of conventional strain gauges (SGs) were placed along the longitudinal rebars to measure the internal strain changes due to the applied loading and to identify local yielding and rebar extension. According to internal force analyses, for beams $\mathrm{O}(\mathrm{O} 1$ \& $\mathrm{O} 2)$ with one opening and beams $\mathrm{T}(\mathrm{T} 1 \& \mathrm{~T} 2)$ with three openings, all the openings were located in both shear and flexure zones.

For the cyclic loading test shown in Figure 5, the beams were simply positioned on the supports. Moreover, two 
TABLe 2: Test beam details.

\begin{tabular}{|c|c|c|c|c|c|c|}
\hline \multirow{2}{*}{ Beam } & \multirow{2}{*}{ Cross section $\left(\mathrm{mm}^{2}\right)$} & \multirow{2}{*}{ Opening } & \multicolumn{2}{|c|}{ Tensile reinforcement } & \multirow{2}{*}{ Compressive reinforcement } & \multirow{2}{*}{ Concrete strength $(\mathrm{MPa})$} \\
\hline & & & Amount & Ratio & & \\
\hline $\mathrm{R}$ & $400 \times 680$ & - & $6 \phi 12$ and $10 \phi 12$ & 0.0067 & $10 \phi 12$ and $2 \phi 12$ & 41.6 \\
\hline $\mathrm{O}(\mathrm{O} 1, \mathrm{O} 2)$ & $400 \times 680$ & 1 & $6 \Phi 12$ and $10 \phi 12$ & 0.0067 & $10 \phi 12$ and $2 \phi 12$ & 42.0 \\
\hline $\mathrm{T}(\mathrm{T} 1, \mathrm{~T} 2)$ & $400 \times 760$ & 3 & $4 \phi 12$ and $10 \phi 12$ & 0.0052 & $11 \phi 12$ & 41.8 \\
\hline
\end{tabular}

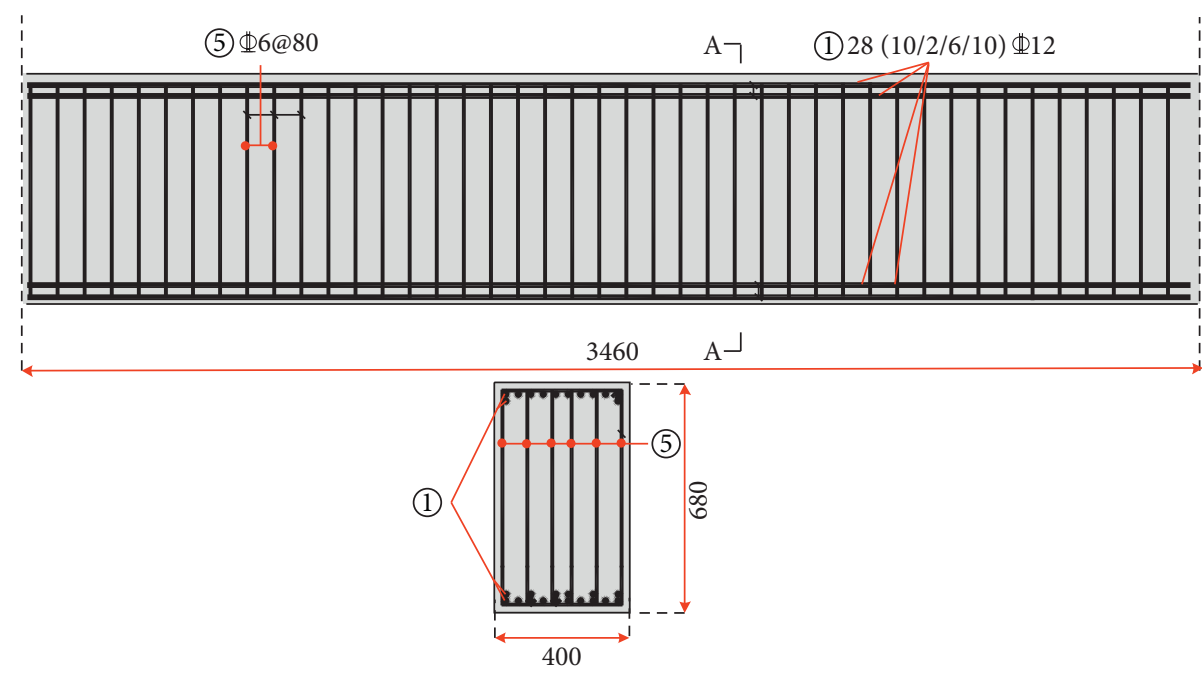

Section A-A

Figure 1: Beam R: reinforcement arrangement (mm).
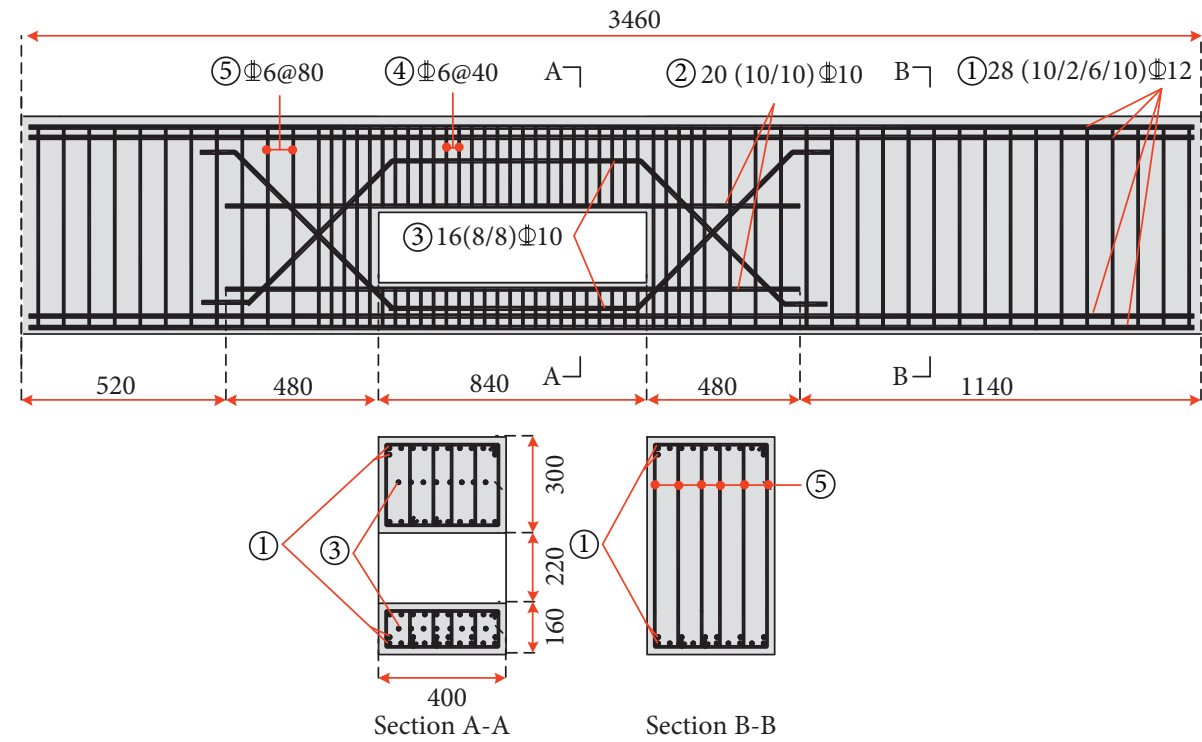

Figure 2: Beam O: reinforcement arrangement (mm).

hydraulic cylinders exerting no force were fixed on the ends of the beam to restrict its entire vertical movement during the loading process. The loads from four JT hydraulic cylinders were concentrated on tripartite points to simulate repeated earthquake loads. The settlement of the two supports, the displacements at the tripartite points, and the deflections of the midspan were collected with five LVDTs.
All the measured data were recorded with a computerized data acquisition system.

For the cyclic loading test, $50 \%, 75 \%, 90 \%$, and $100 \%$ of the yield load estimated from the static tests were exerted on the beam by the JT1 or JT2 hydraulic cylinders to produce one forward (downwards) and one reversed (upwards) loading for each step. After reaching the cyclic 


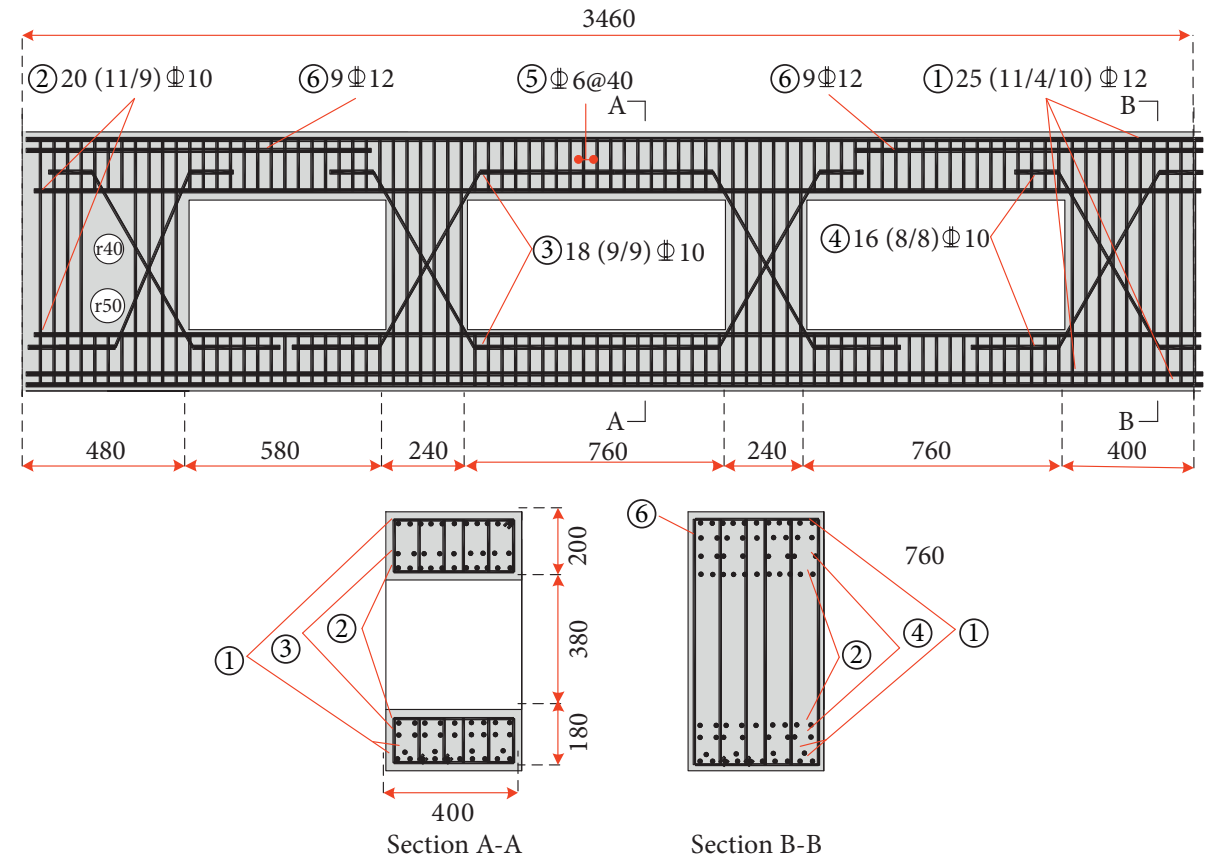

Figure 3: Beam T: reinforcement arrangement (mm).

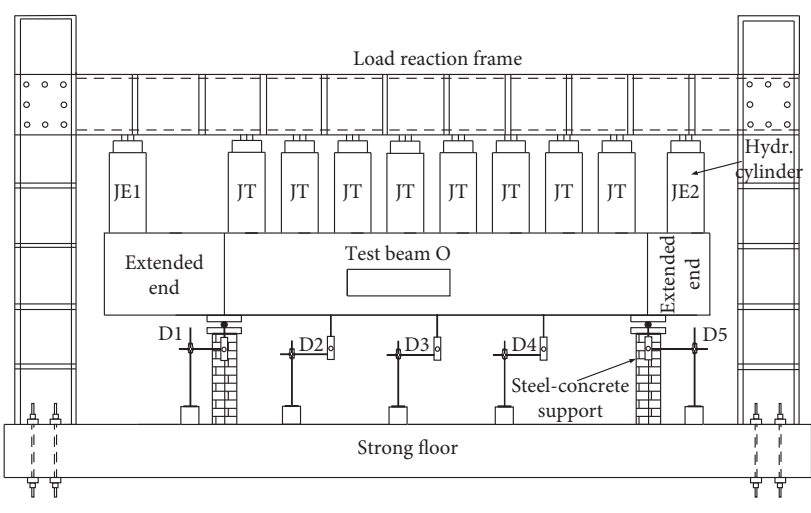

(a)

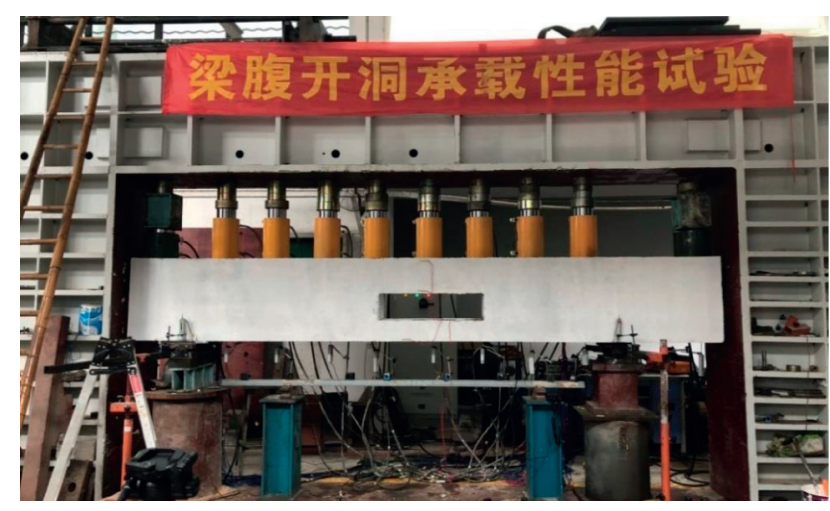

(b)

FIgUre 4: Static test setup. (a) Setup schematic. (b) Setup photograph.

yield load, a group of loadings, including one forward loading and one reversed loading, was set to apply positive and negative yield displacements, respectively. Each group of loadings lasted for 10 minutes and was repeated three times. The process was repeated, and both loadings were then set to apply double yield displacements $\left(2 \delta_{y}\right)$, triple yield displacements $\left(3 \delta_{y}\right)$, etc., until the specimens could no longer be loaded.

In both tests, the loading points were set to be equally distributed to prevent asymmetrical loading. The loading pattern was determined by simulating earthquake actions according to relative specifications. In the cyclic loading tests, the opening of beam $\mathrm{O}$ was located in the pure flexure zone, the middle opening of beam $\mathrm{T}$ was located in the pure flexure zone, and the left and right openings of beam $\mathrm{T}$ were located in both shear and flexure zones.

\section{Static Test Results and Analysis}

4.1. Loading Process. Figure 6 illustrates the fracture patterns observed in the static loading tests of the beams. In both tests, the occurrence of cracks was sorted in chronological order from No. 1 to No. 4. For beam O, vertical cracks initiated in the concrete below the web opening, and these cracks were labelled "No. 1" in Figure 6(a). As the load increased, shear cracks initiated from hydraulic cylinder JE1 and propagated towards the support on the left side; these cracks were labelled "No. 2" in Figure 6(a). Afterwards, the cracks labelled "No. 3" in Figure 6(a) were observed in the bottom of the beam on the left and right sides. Then, $1 \mathrm{~m}$ from the opening, a main flexural-shear crack extended from the bottom to the top of the beam, forming a through crack and resulting in concrete spalling. Thereafter, the cracks 


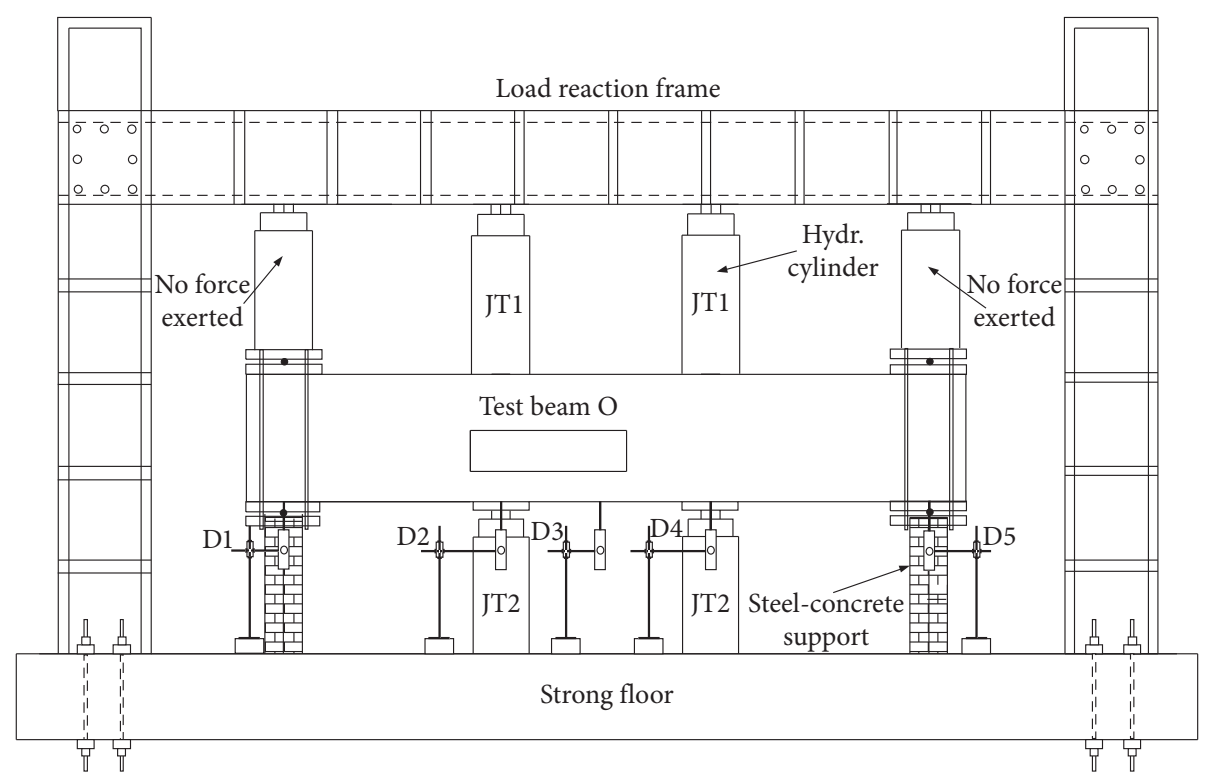

(a)

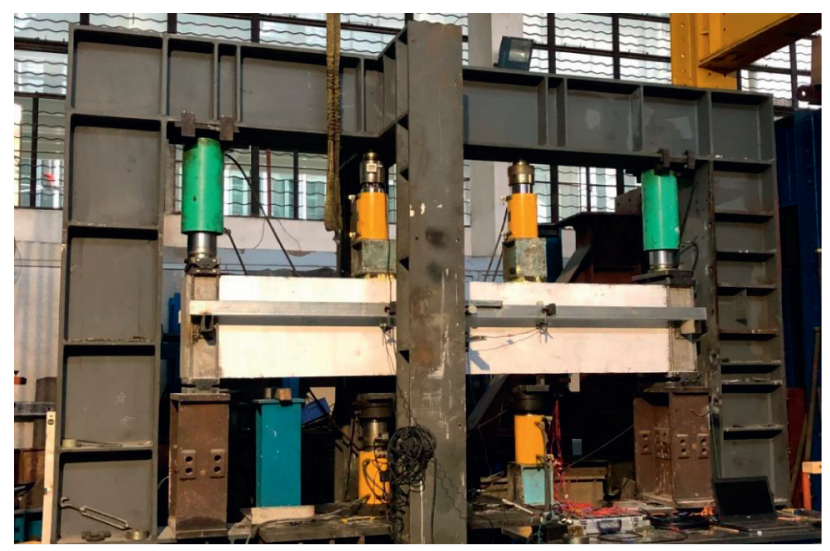

(b)

Figure 5: Cyclic test setup. (a) Setup schematic. (b) Setup photograph.

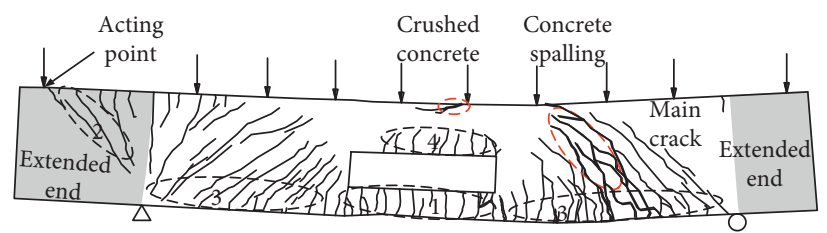

(A)

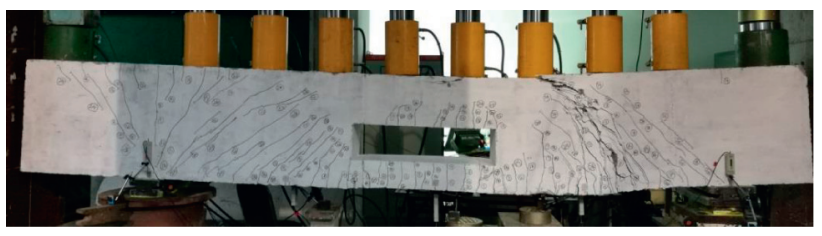

(B)

(a)

Figure 6: Continued. 


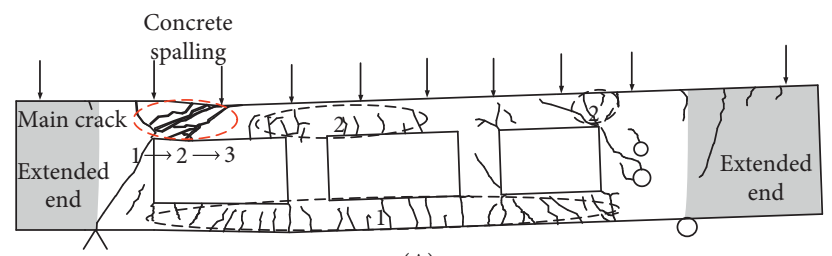

(A)

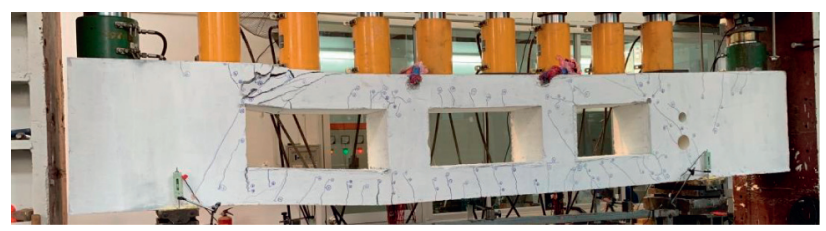

(B)

(b)

Figure 6: Failure sketches for the specimens. (a) Beam O: (A) crack schematic and (B) crack photograph. (b) Beam T: (A) crack schematic and (B) crack photograph.

labelled "No. 4" in Figure 6(a) initiated and the through crack extended. Finally, the concrete at the top of the beam was crushed, triggering the test piece to lose its loadbearing capacity. Before the test beam fractured, the component presented an intense deflection, evident signs of damage, and promising ductility.

Figure 6(b) shows the crack schematic and photograph for the test specimen with three openings (beam T). Vertical cracks first emerged in the concrete below the three web openings, and then the concrete in the top of the left web opening cracked as the load increased. Later, the main crack extended through the beam, and concrete spalling was observed. Compared to beam $\mathrm{O}$, beam $\mathrm{T}$ contained fewer cracks.

4.2. Ductility and Rigidity. The load-deflection curves of the specimens are illustrated in Figure 7. Table 3 tabulates the deformation ductility indices $(u)$ and the stiffness of the specimens. The indices $(u)$ are the ratio of the midspan deflection at the ultimate load to that at the yielding of the tensile reinforcement, which represents the deformation capacity of the beam. The equivalent yield points in both curves were determined using the Park method with a load factor of 0.75 [23]. The initial secant stiffness represents the initial value at the very beginning of the test, whereas the average stiffness corresponds to the average value in the linear stage up to yielding. Since it is cumbersome to determine the specific value of the moment-curvature curve in the test beams, the slope of the load-deflection curves was used for the stiffness calculation. Five marks were positioned on both curves, representing five different loading states: crack (first crack observed), normal use (engineering design load), $W_{\max }=0.1$ (maximum crack width reaching $0.1 \mathrm{~mm}$ ), $W_{\max }=0.2$, and $W_{\max }=0.3$. The failure state was defined when a sudden offload was detected on the hydraulic cylinders.

For the test of beam $\mathrm{O}$, the obtained yield load was $328.9 \mathrm{kN}$, which was $65.9 \%$ larger than the yield load of beam $\mathrm{T}(198.2 \mathrm{kN})$. The ultimate load for beam O was $396.1 \mathrm{kN}$, which was $20.4 \%$ larger than its yield load. The results clearly suggest that increasing the number of openings significantly decreased the loadbearing capacity of a beam. As illustrated in Figure 7, cracks initiated before the sustained load reached the engineering design load, which is indicative that even under design loads, cracks propagated in beams with openings.

Compared to beam O, beam $\mathrm{T}$ exhibited a $16.7 \%$ lower deformation ductility index, a $41.4 \%$ lower initial secant stiffness, and a $16.3 \%$ lower average stiffness. These results can be primarily attributed to the smaller opening area in beam O $\left(184800 \mathrm{~mm}^{2}\right)$ compared to that in beam $\mathrm{T}$ $\left(798000 \mathrm{~mm}^{2}\right)$. The average stiffness of beam $\mathrm{T}$ was only $16.3 \%$ smaller than that of beam $\mathrm{O}$, whereas the opening area was $331.8 \%$ larger. The small decrease in the average stiffness caused by the larger opening area can be ascribed to the effect of the heavier local reinforcements around the three openings.

4.3. Steel Reinforcement Strain Analysis. The strains in beam $\mathrm{O}$ were collected along the steel reinforcements according to the schematic diagram in Figure 8. The strain gauges were adhered to two side faces of the steel cage of the reinforcements, which are labelled "A" and "B". The average value $\mathrm{G}(n)$ was taken from the two strains monitored at the same positions of the two side faces. The loads applied by the JT hydraulic cylinders and the corresponding maximum crack width measured in the beam are listed in Table 4. To better understand the reinforcement stress status, the measured strains were then converted into stresses for analysis.

To directly illustrate the stress evolution chronologically, the measured stress values were arranged according to different loading stages in Figure 9. The stress values measured with gauge 1 and gauge 2 show that the longitudinal rebars in the upper chord were compressed at the top, whereas tensile stresses were also detected in the bottom, exhibiting the features of the so-called "trabecular beam." Like ordinary structural beams, the longitudinal 
rebars in the lower chord were tensioned. Therefore, both typical beam-type loading and trabecular beam loading patterns were observed during the testing of this specimen. Moreover, an interesting trend was also observed in the stress variation curves monitored at different gauges. As shown in Figure 9, for the area surrounding the web opening, smaller tensile or compressive stresses were detected in the gauges (G6 and G9) closer to the geometric centreline compared to those (G5, G7 and G8, G10) away from the centreline in the same row. During the entire loading process, all the stresses, compressive or tensile, increased as the exerted force increased until specimen failure. Upon reaching the failure state, nearly all the steel reinforcements yielded, showing an effective utilization of the steel strength.

Figure 10 illustrates the evolution of the stresses in the longitudinal rebars in the bottom of the beam during the loading process. Since the longitudinal rebars under the web openings were basically located in the middle of the beam, their stresses increased evenly with the exerted force. Moreover, for the strain gauges near this area, few strain increments were observed. When the load from the JT hydraulic cylinder reached approximately $200 \mathrm{kN}$, the longitudinal stress in the rebar near this area started to increase sharply. Finally, the longitudinal reinforcements in the lower chord yielded entirely.

The distributions of the strain gauges in beam $\mathrm{T}$ are shown in Figure 11. Similar to those in beam O, both side faces (A and B) of the steel cages in beam $\mathrm{T}$ are monitored to collect steel strain at a specified position. The relationship between the loads applied by the JT hydraulic cylinders and the maximum crack width measured in the beams is presented in Table 5 .

The load on the upper chord was similar to that of the abovementioned "trabecular beam," and the longitudinal rebars at the bottom of the chord were mainly subjected to a tensile load. Under the same load, the stress in the longitudinal rebars of the upper chord in the right opening was generally smaller than that in the left opening, as shown in Figure 12 . This phenomenon can be primarily attributed to the larger area of the right opening, and the stiffness of the right-side section was weakened to a greater extent. The reinforcements in the corner of the right opening sustained compressive stresses, as indicated by gauge 9 ; crushed concrete was observed in this location, as shown in Figure 6. A dislocation around the crushed concrete was also identified. The different stress evolution trends shown by gauge 9 , the corner concrete crushing, and the corner dislocation may all result from the stress concentrations induced by sharp corners and the weakened stiffness in the right-side section.

The longitudinal rebars in the upper row of the lower chord were mainly subjected to tensile stresses, and a small number of strain gauges (G13 and G17) also initially detected compressive stresses, as shown in Figure 13. Considering the positions of gauges 13 and 17, the torsional deformation of the openings was believed to lead to the presence of corner compression. As beam $\mathrm{T}$ progressed towards the failure state, the final sharp growth in reinforcement stress could be explained by the dense concrete cracking. The stresses measured with gauge 19 were generally greater than those of other gauges but still smaller than

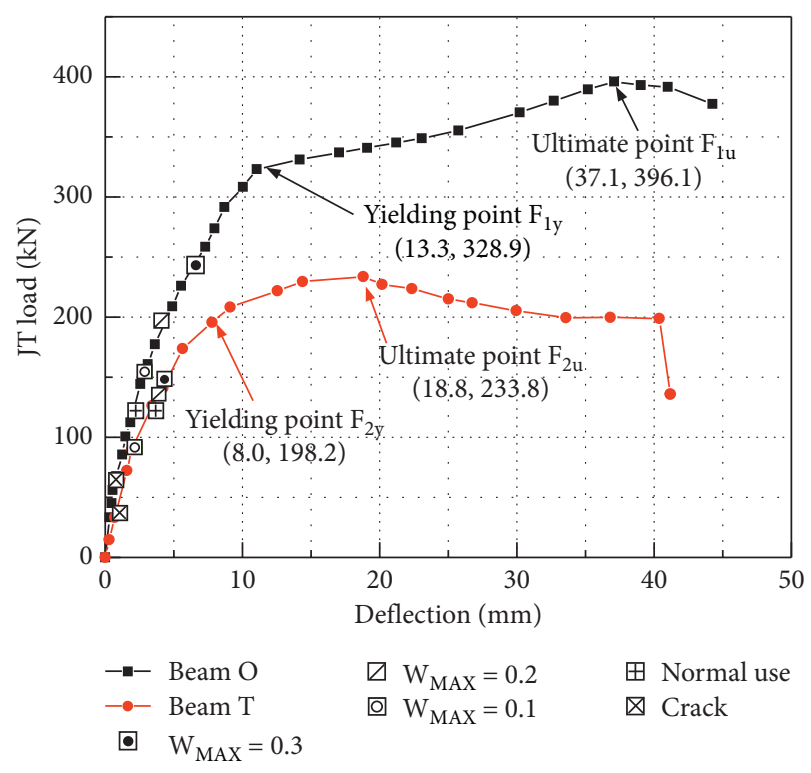

Figure 7: Load-deflection curves of the specimens.

Table 3: Ductility and stiffness of specimens.

\begin{tabular}{lccc}
\hline \multirow{2}{*}{ Beam } & \multirow{2}{*}{ Deformation ductility index } & \multicolumn{2}{c}{ Stiffness $(\mathrm{kN} / \mathrm{mm})$} \\
Initial secant & Average \\
\hline $\mathrm{O}$ & 2.81 & 70.80 & 35.71 \\
$\mathrm{~T}$ & 2.34 & 41.49 & 29.88 \\
\hline
\end{tabular}

the reinforcement yield strength. For the steel stress evolution in the lower row of the lower chord, the overall growth of the longitudinal steel bars was relatively uniform, as shown in Figure 14. Similarly, under the same load, the stress values besides the right opening were generally smaller due the weakened stiffness of the right side of the test beam. The tensile stresses measured with gauge 23 were larger than those of the other gauges from the beginning to the end. In both beam tests, the "trabecular beam" behaviour was detected. The upper chord longitudinal reinforcements can also be subjected to tension. According to the steel stress analysis above, the reinforcement stresses in beam $\mathrm{T}$ were basically smaller than those in beam $\mathrm{O}$, which could be attributed to the smaller loadbearing capacity of beam $\mathrm{T}$.

Due to a torsional deformation of the openings and the stress concentration induced by sharp corners, the corners of the opening were shown to be the weak parts of beams with openings. Therefore, corner strengthening should be taken into consideration during the service of beams with openings. The results obtained in this test can be adopted as optimization suggestions in practical subway station design, construction, and maintenance.

\section{Cyclic Test Results and Discussion}

5.1. Loading Process. The cyclic tests were conducted in accordance with the procedure described in Section 3.2, and Figure 15 shows the fracture pattern of the reference beam $\mathrm{R}$. 


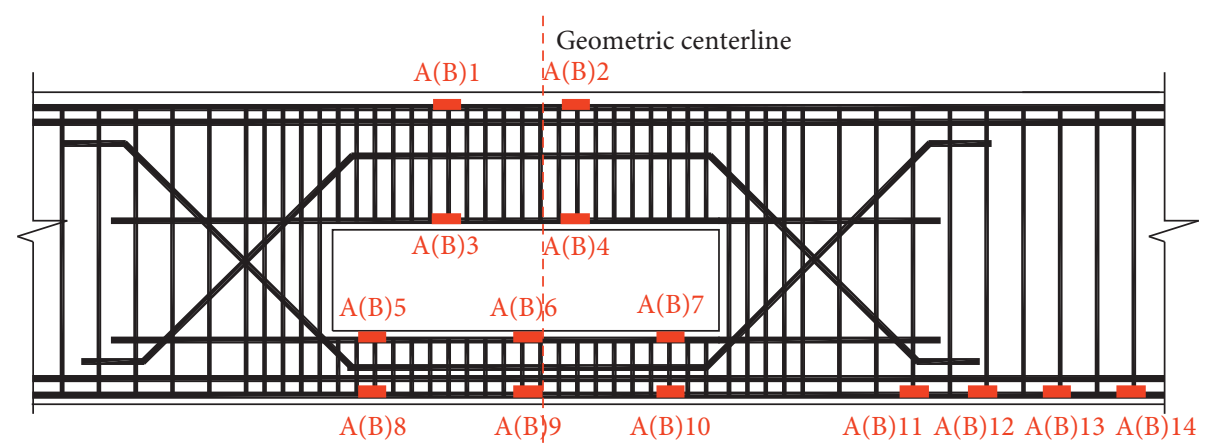

Figure 8: Beam O: strain gauge measurement schematic diagram.

TABLE 4: Load applied by the JT hydraulic cylinders under different crack widths (beam $\mathrm{O}$ ).

\begin{tabular}{lccccccccc}
\hline $\begin{array}{l}\text { Crack width } \\
(\mathrm{mm})\end{array}$ & 0.02 & 0.04 & 0.08 & 0.14 & 0.16 & 0.20 & 0.22 & 0.30 & 1.80 \\
\hline Load $(\mathrm{kN})$ & 56 & 67.2 & 128 & 176 & 192 & 240 & 272 & 304 & 336 \\
\hline
\end{tabular}

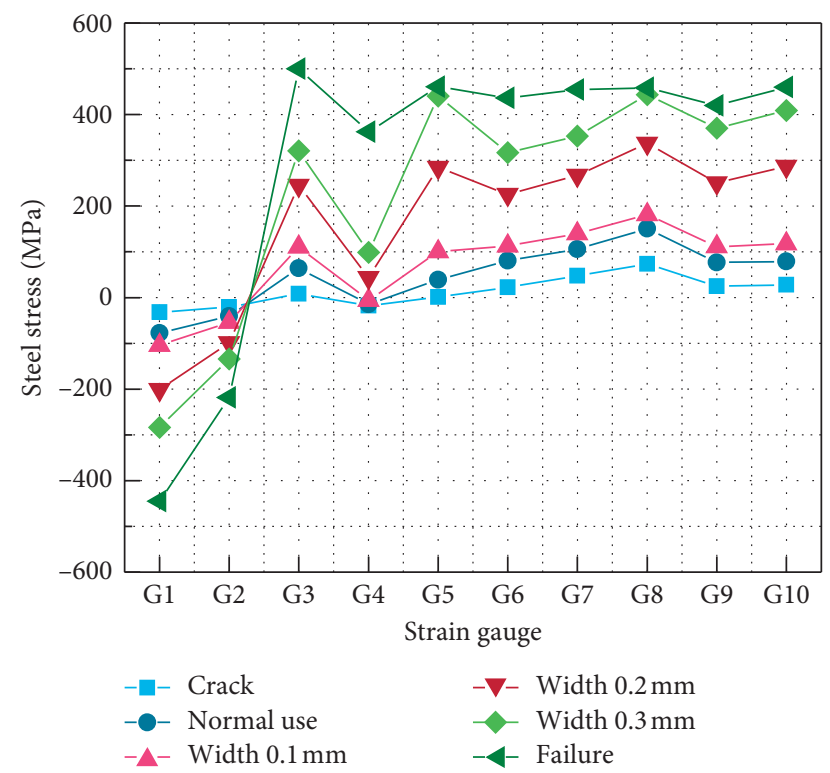

Figure 9: Beam O: steel stress evolution near the web opening.

When the reverse load applied from the bottom first reached $200 \mathrm{kN}$, cracks initiated on the top of beam R; these cracks are labelled "No. 1" in Figure 15(a). The maximum measured crack width was $0.10 \mathrm{~mm}$, and the measured midspan displacement was $1.76 \mathrm{~mm}$. Then, a forward load of $200 \mathrm{kN}$ was applied from the top, and cracks initiated between the bottom loading points; these cracks are labelled "No. 2" in Figure 15(a). The induced maximum crack width was measured as $0.10 \mathrm{~mm}$, and the corresponding midspan displacement was $1.78 \mathrm{~mm}$. Due to the reciprocating cycle, the cracks generated on the top of the beam by the reverse loading were closed due to the compression induced by forward loading. When the reverse load increased to $375 \mathrm{kN}$, the measured strain indicated that the top steel reinforcements started to yield. The reverse yield displacement $u_{y}$ was

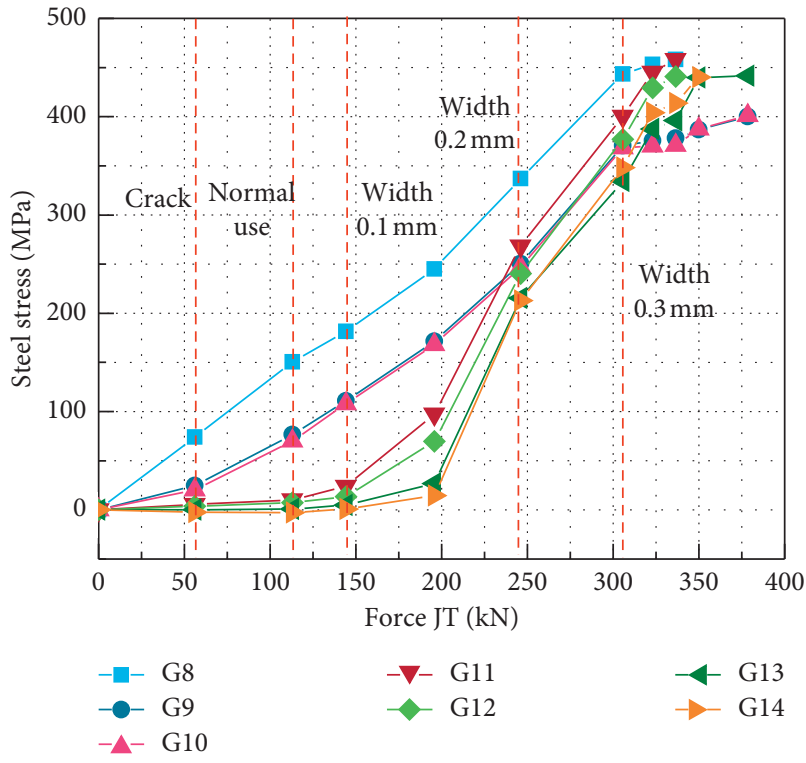

FIgUre 10: Beam O: steel stress evolution in the lower chord.

$5.10 \mathrm{~mm}$, and the maximum crack width within region No. 1 was measured as $0.22 \mathrm{~mm}$. When the forward load increased to $435 \mathrm{kN}$, the reinforcements in the bottom yielded, and the cracks developed further. The forward yield displacement $u_{y}^{\prime}$ was $6.00 \mathrm{~mm}$. The reason why the forward yield displacement was larger than that induced by the reverse loading can be attributed to the additional reinforcements in the bottom of the beam.

Afterwards, each step was implemented by an increment in the reverse yield displacement $u_{y}$ and the forward yield displacement $u_{y}^{\prime}$. After the reverse displacement reached $-2 u_{y}$ (“" forward loading), the maximum crack width was measured to be $1.04 \mathrm{~mm}$. As the forward displacement increased to $+2 u_{y}^{\prime}$, the maximum crack width reached $1.24 \mathrm{~mm}$. When the cycling loading was applied, the beam was densely cracked. After the displacements exceeded $-4 u_{y}$ and $+4 u_{y}^{\prime}$, concrete spalling was observed on the top and bottom of the test beam, and the crack width measurements were stopped. As the displacements increased to $-5 u_{y}$ and $+5 u_{y}^{\prime}$, the cracks penetrated along the beam height, as illustrated in Figure 15(a). Finally, when a reverse displacement of $-8 u_{y}$ 


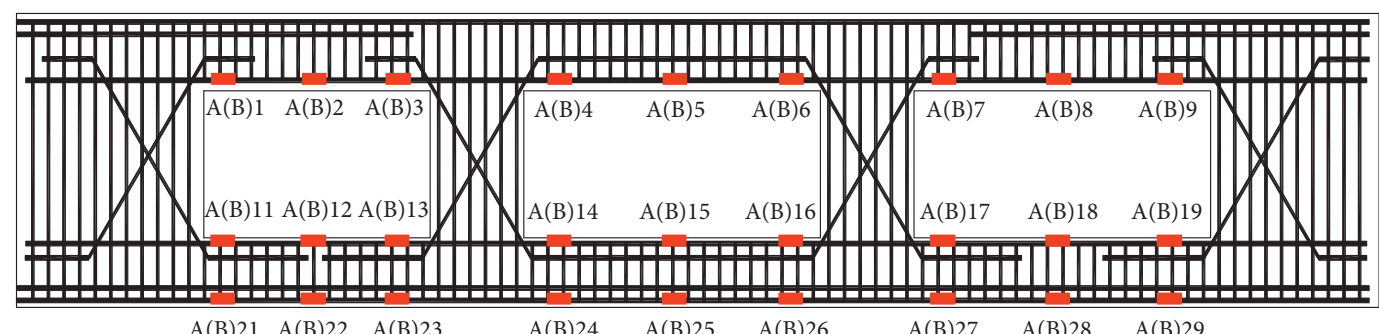

$\mathrm{A}(\mathrm{B}) 21 \quad \mathrm{~A}(\mathrm{~B}) 22 \quad \mathrm{~A}(\mathrm{~B}) 23$

A(B)24 $\quad$ A(B) $25 \quad$ A(B)26

$\begin{array}{lll}A(B) 27 & A(B) 28 & A(B) 29\end{array}$

Figure 11: Beam T: strain gauge measurement schematic diagram.

TABLE 5: Load applied by the JT hydraulic cylinders under different crack widths (beam $(\mathrm{T})$.

\begin{tabular}{lccccccc}
\hline Crack width $(\mathrm{mm})$ & 0.02 & 0.04 & 0.08 & 0.14 & 0.16 & 0.20 & 0.30 \\
\hline Load $(\mathrm{kN})$ & 41 & 69 & 88 & 106 & 113 & 132 & 147 \\
\hline
\end{tabular}

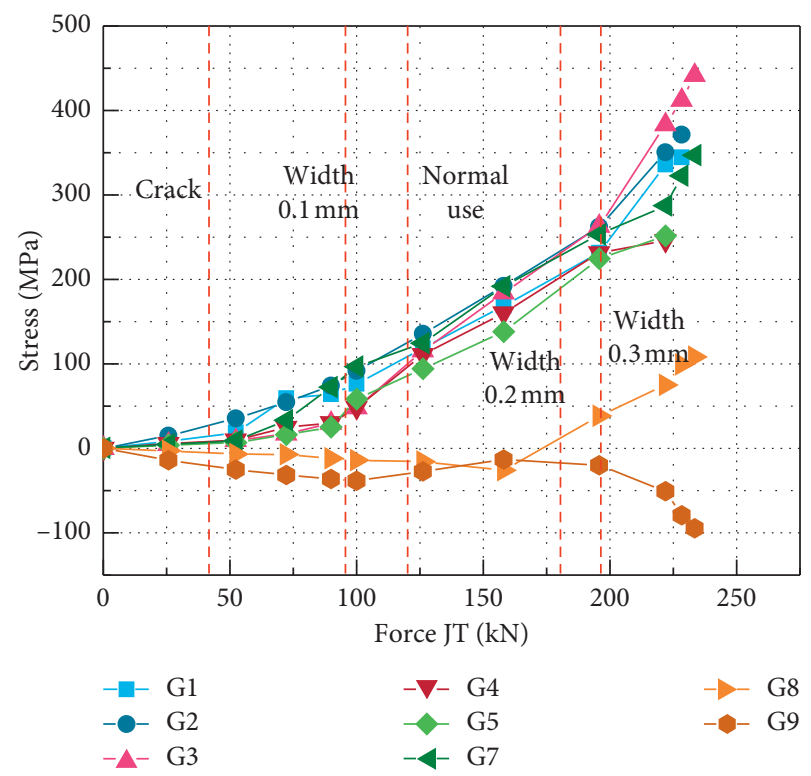

Figure 12: Beam T: steel stress evolution in the upper chord.

was implemented, the steel bar audibly failed, and the load could no longer be exerted.

As shown in Figure 16, under reverse loading, cracks initiated between the top loading point with a maximum crack width of $0.02 \mathrm{~mm}$ and a midspan displacement of $0.85 \mathrm{~mm}$. When the reverse load increased to $530 \mathrm{kN}$, the strain gauge measurements indicated that the top reinforcements began to yield. At this time, the corresponding reverse yield displacement was $7.00 \mathrm{~mm}$, and the maximum crack width was $0.20 \mathrm{~mm}$. After the forward load reached $620 \mathrm{kN}$, the strain gauge measurements indicated that the steel rebar yielded, and the forward yield displacement was $8.00 \mathrm{~mm}$.

As the loaded reverse displacement increased to $-2 u_{2 y}$, the maximum crack width at the loading point developed rapidly, reaching $1.80 \mathrm{~mm}$. When the loaded displacement further increased to $-3 u_{y}$ and $+3 u_{y}$, concrete spalling was

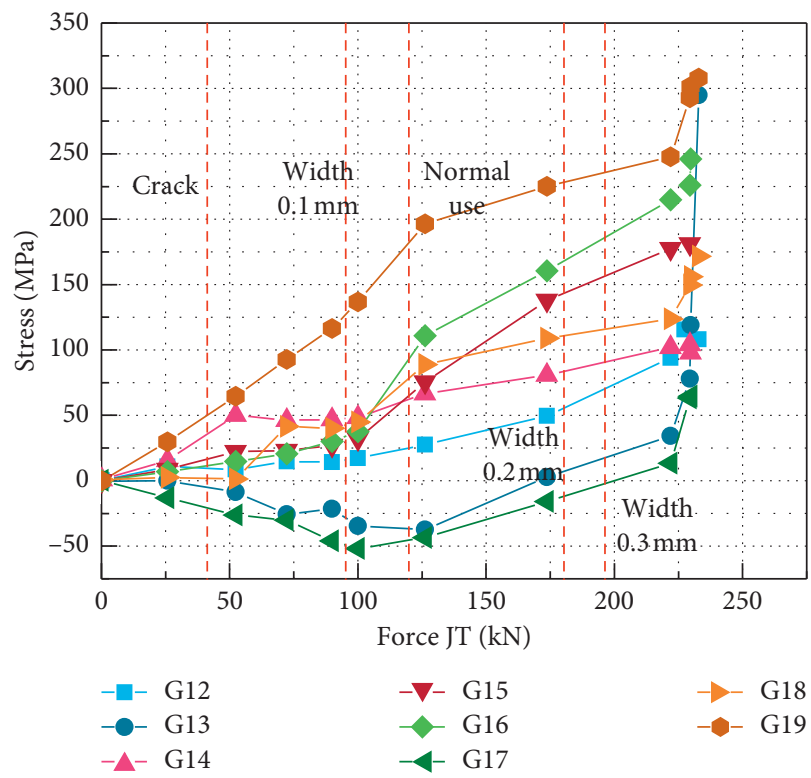

Figure 13: Beam T: steel stress evolution in the upper row of the lower chord.

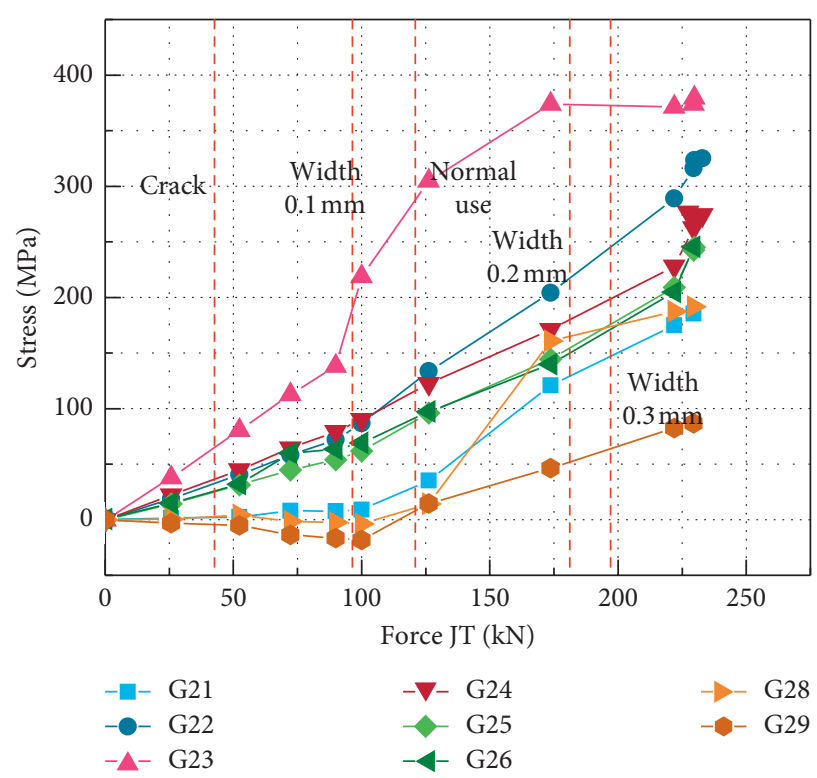

FIgURE 14: Beam T: steel stress evolution in the lower row of the lower chord. 
observed near the right loading points at the top and the bottom. The cracks penetrated along the beam height, as illustrated in Figure 16(a). Finally, when the loaded displacement reached $-4 u_{y}$ and $+4 u_{y}$, the reinforcements audibly failed, after which the test was ended.

The cracks penetrated vertically along the loading directions in the reference beam. However, during the cyclic test of the beam with only one opening, penetrating cracks were found between the web opening and the right-side loading points. Above and beneath the web opening, dense cracks were found developing vertically from two edges along the beam height. For both test beams, those uncentred cracks propagated at an incline towards the centreline along the beam height.

As shown in Figure 17, the initial cracks began to form when the reverse load reached $120 \mathrm{kN}$. The measured maximum crack width was $0.04 \mathrm{~mm}$, and the midspan displacement was $1.36 \mathrm{~mm}$. When the reverse load reached $400 \mathrm{kN}$, the measured strain indicated that the reinforcements at the top yielded, and the corresponding reverse yield displacement $u_{3 y}$ was measured as $10.29 \mathrm{~mm}$. After the forward load reached $400 \mathrm{kN}$, the measured forward yield displacement $u_{3 y}^{\prime}$ was $11.18 \mathrm{~mm}$.

As the loaded displacement increased to $-2 u_{3 y}$, the largest crack in the beam top propagated rapidly, reaching $1.80 \mathrm{~mm}$. When the test specimen was loaded to $+2 u_{3 y}$, concrete spalling was observed around the right-side opening, as illustrated in Figure 17(a). After the loaded displacement reached $-3 u_{3 y}$ and $+3 u_{3 y}$, the cracks penetrated along the beam height. Finally, at $4 u_{3 y}$, a large area of concrete spalling was observed, after which the test was ended.

Compared to the reference beam and the beam with only one opening, fewer cracks were identified in the cycling test of the beam with three openings. However, the concrete spalling was more severe in the beam with three openings. A large area of concrete spalling around the right-side web opening suggested a much more weakened stiffness on the right section of the test beam. Table 6 summarizes the key characteristics of the load-deflection responses of the underground metro station RC beams with various openings under static and cyclic loading conditions.

\subsection{Analysis of the Cyclic Test Results}

5.2.1. Hysteresis Behaviour and Energy Dissipation. The hysteresis loops from the three specimens are illustrated in Figure 18. The hysteresis loops of beam R exhibit the largest hysteretic damping, whereas those of beam $\mathrm{T}$ exhibit the smallest hysteretic damping. During the preloading period, especially before crack initiation, the load-displacement curve increased substantially linearly during the loading and unloading process. As the load increased, the damage accumulated with the development of cracks along with residual deformation. For the reference beam (beam R), after the longitudinal reinforcements yielded, the subsequent three cycling loops were basically coincident, which indicates slight concrete damage. For the beam with only one opening (beam O), the hysteresis loops also coincided before the triple yield displacement was implemented. During its fourth yield displacement cycle, the beam was obviously damaged. For the beam with multiple openings (beam T), apparent damage was already observed during the double and triple yield displacement cycles.

A spindle shape was the most ideal shape for the hysteresis loops, which indicated that the reference beam exhibited strong energy dissipation ability. Moreover, the envelope of the hysteresis curve of beam $\mathrm{O}$ was slightly narrower than that of beam $R$. The reverse sigmoidal hysteresis loops of beam $\mathrm{T}$ indicated that its energy dissipation ability was greatly impacted by the openings.

An interesting trend was also observed when comparing the hysteresis loops. Since the chord and diagonal reinforcements were densely arranged around the opening, the forward ultimate load and the reverse ultimate load of beam $\mathrm{O}$ were $33 \%$ and $23 \%$ larger than those of beam $\mathrm{R}$, respectively. Arranging denser reinforcements around the opening effectively improved the ultimate loadbearing capacity but weakened the ductility of the beam.

Figure 19 shows the energy dissipation capacities of the three beams obtained from the cyclic tests. These results show that the energy dissipation capacity of beam $T$ was the weakest. Under the same midspan displacement, the energy consumption of beam $\mathrm{O}$ was close to or better than that of beam $R$. This phenomenon can be primarily attributed to the reinforcements around the opening effectively suppressing the generation and development of cracks. Later, after reaching the peak load, the energy dissipation capacity of beam $\mathrm{T}$ degraded.

Figure 20 shows the comparison of the equivalent damping coefficients of the three specimens. Under the same midspan displacement, the equivalent damping coefficient curves of beam $\mathrm{O}$ and beam $\mathrm{R}$ were basically consistent in the early stages. As loading increased, the equivalent damping coefficient evolution curve of beam $\mathrm{O}$ separated from that of beam $\mathrm{R}$, indicating that strengthening from the reinforcements around the opening cannot completely compensate for the impact on energy dissipation. Moreover, the forward and reversed equivalent damping coefficients of beam T were relatively small during the whole loading process, showing a weaker energy dissipation capacity.

5.2.2. Ductility Performance Analysis. Figure 21 compares the skeleton curves of the three specimens in the cyclic tests. The forward and reverse yield loads of beam $\mathrm{O}$ were larger than those of the other two beams, which is consistent with the results provided above. For beam T, yielding occurs earlier due to the weakening of the beam section by the multiple openings. Moreover, under the same load, beam Texhibited the largest displacement. After yielding, beam $\mathrm{R}$ continued to sustain multiple yield displacements with a mild curve segment, showing promising ductility.

The average displacement ductility ratios of beam $\mathrm{R}$, beam $\mathrm{O}$, and beam $\mathrm{T}$ were $5.13,4.20$, and 3.20 , respectively. 


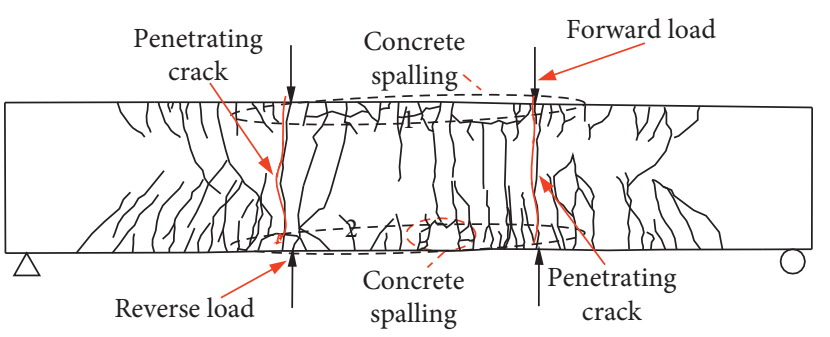

(a)

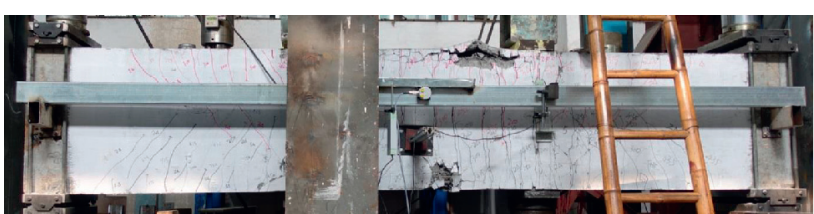

(b)

Figure 15: Beam R: (a) crack schematic and (b) crack photograph.

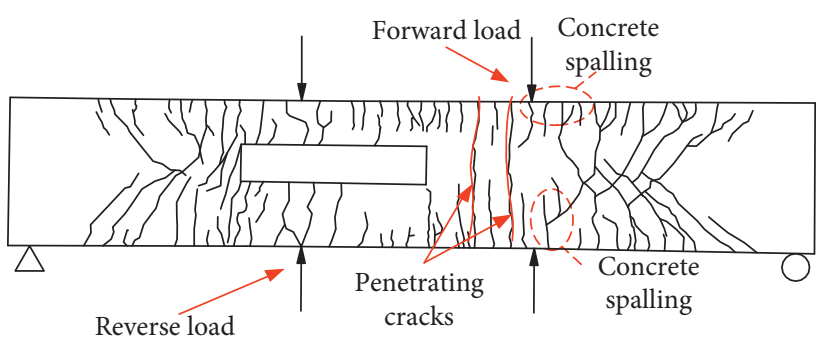

(a)

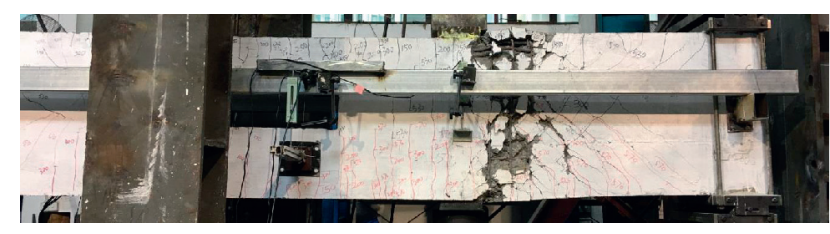

(b)

Figure 16: Beam O: (a) crack schematic and (b) crack photograph.

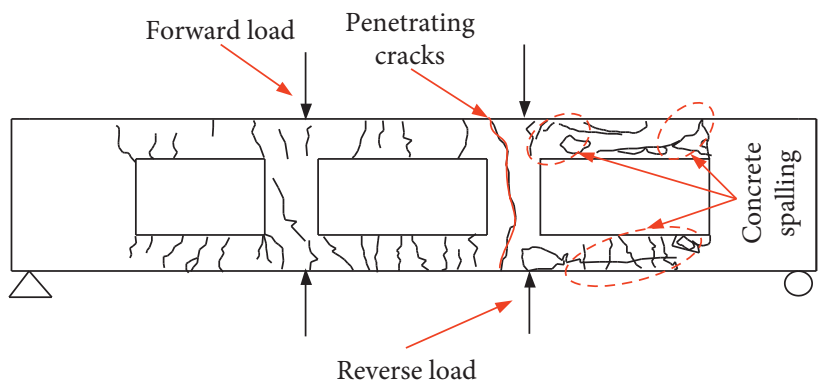

(a)

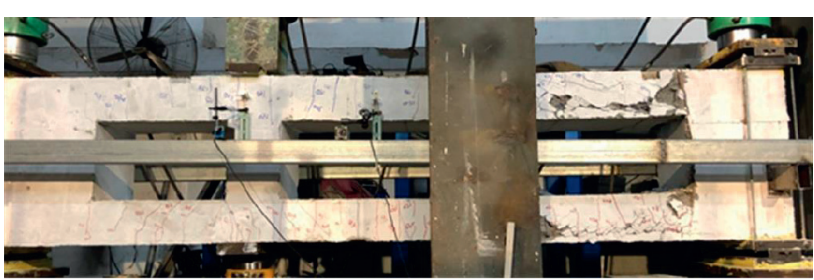

(b)

Figure 17: Beam T: (a) crack schematic and (b) crack photograph.

TABLE 6: Key characteristics of the load-deflection responses of the RC beams with various openings under static and cyclic loading conditions.

\begin{tabular}{|c|c|c|c|c|c|c|c|}
\hline \multirow{2}{*}{\multicolumn{2}{|c|}{ Specimen }} & \multicolumn{2}{|c|}{ Cracking load (kN) } & \multicolumn{2}{|c|}{ Yield load (kN) } & \multicolumn{2}{|c|}{ Ultimate load $(\mathrm{kN})$} \\
\hline & & Reverse & Forward & Reverse & Forward & Reverse & Forward \\
\hline \multirow{2}{*}{ Static } & Beam O & \multicolumn{2}{|c|}{56} & \multicolumn{2}{|c|}{328.9} & \multicolumn{2}{|c|}{396.1} \\
\hline & Beam $\mathrm{T}$ & \multicolumn{2}{|c|}{41} & \multicolumn{2}{|c|}{198.2} & \multicolumn{2}{|c|}{233.8} \\
\hline \multirow{3}{*}{ Cyclic } & Beam R & 200 & 200 & 375 & 435 & 600.4 & 492.3 \\
\hline & Beam $\mathrm{O}$ & 150 & 150 & 530 & 620 & 740.6 & 652.4 \\
\hline & Beam T & 120 & 120 & 400 & 400 & 487.2 & 433.6 \\
\hline
\end{tabular}

Compared with beam $\mathrm{R}$, the displacement ductility ratios of beam $\mathrm{O}$ and beam $\mathrm{T}$ were reduced by $18.1 \%$ and $37.6 \%$, respectively. Ductile structures with higher displacement ductility are generally able to dissipate significant amounts of energy during cyclic deformations. The more the energy dissipated per cycle without excessive deterioration, the better the behaviour of the structure.

5.2.3. Stiffness Degradation Performance. Figure 22 compares the stiffness degradation curves of the three specimens 


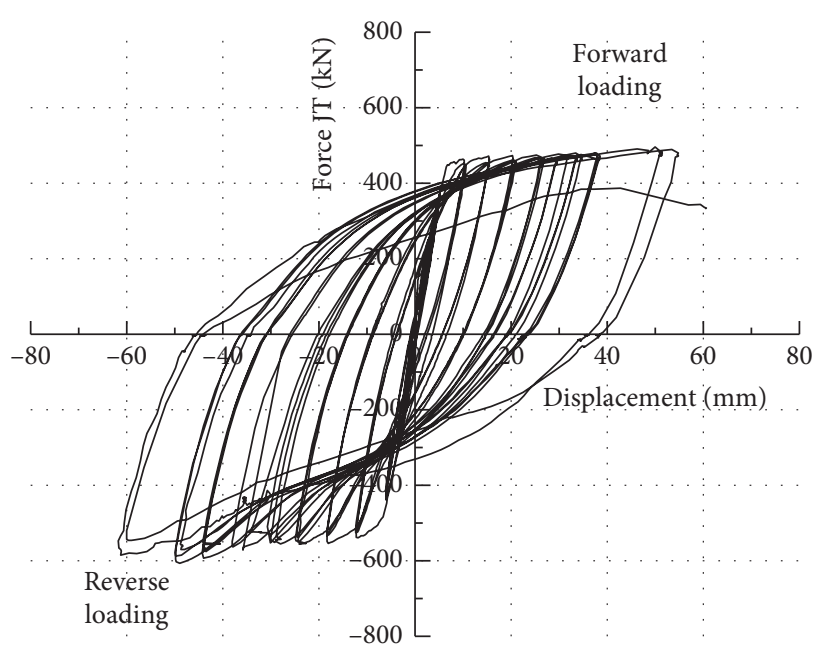

(a)

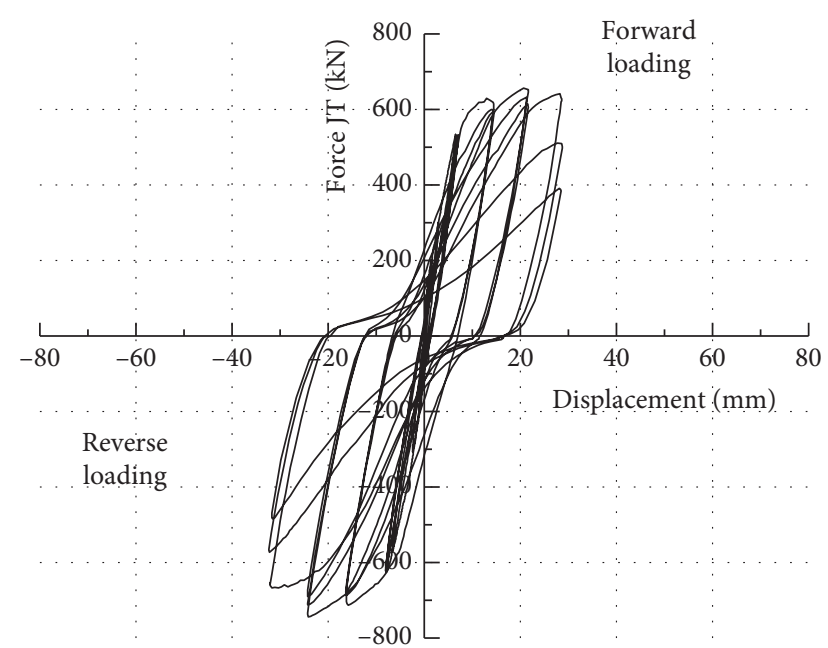

(b)

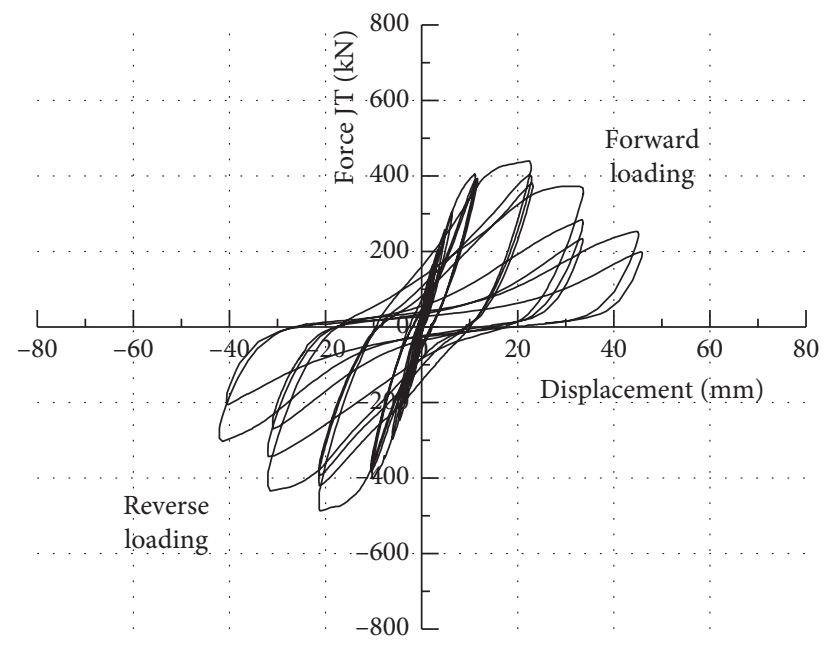

(c)

Figure 18: Hysteresis curves for the test specimens. (a) Beam R. (b) Beam O. (c) Beam T.

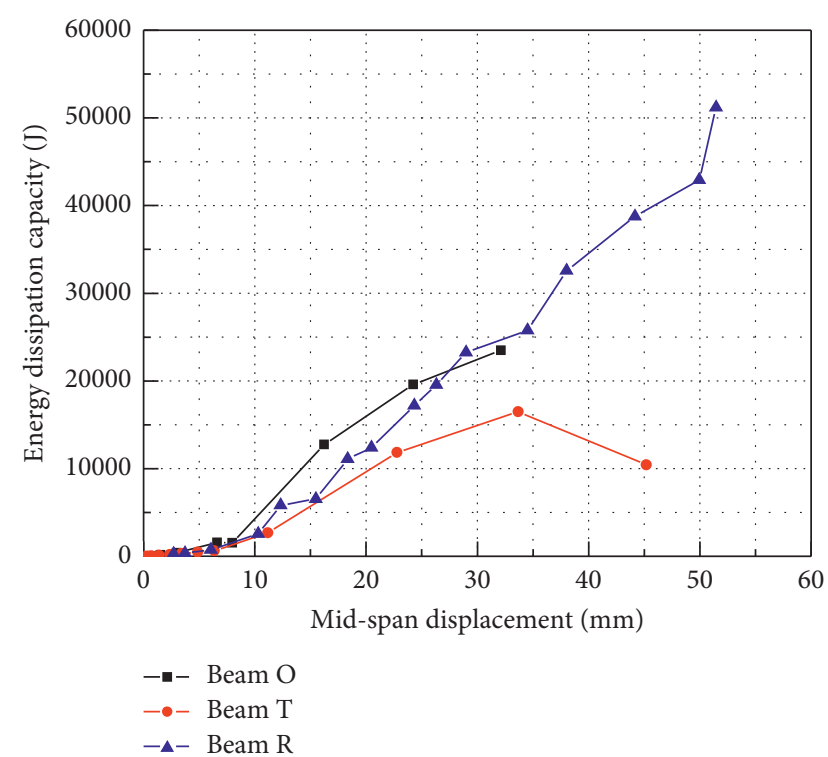

FIGURE 19: Energy dissipation capacity.
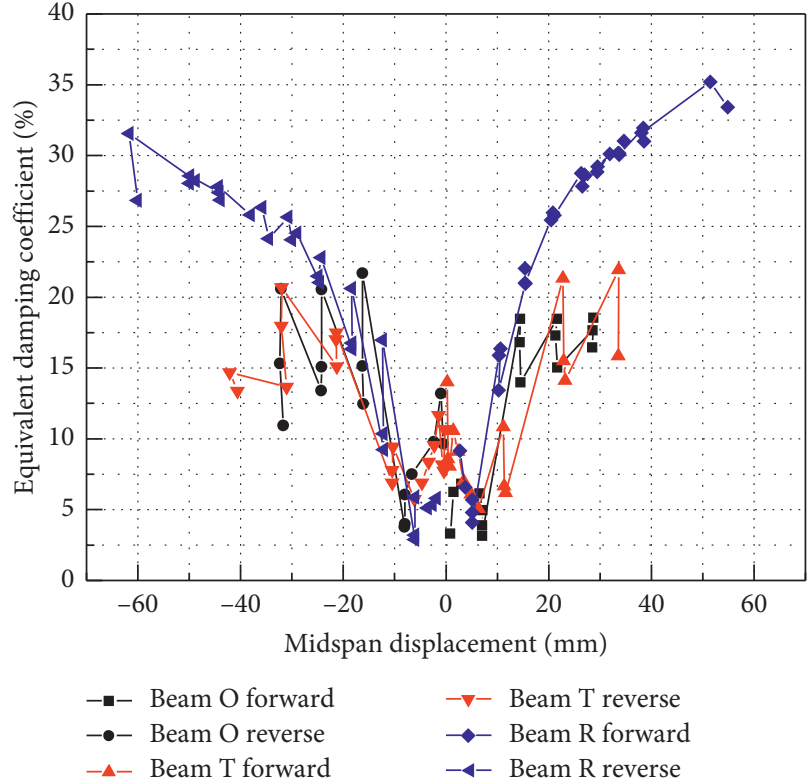

Figure 20: Equivalent damping coefficients. 


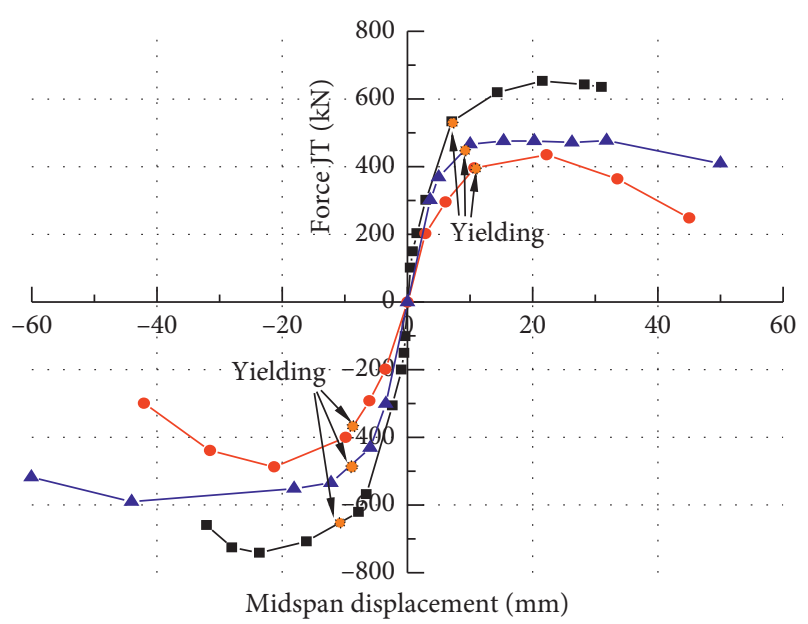

- - Beam O

- - Beam T

$-\Delta-$ Beam R

FIGURE 21: Skeleton curves of the three specimens.

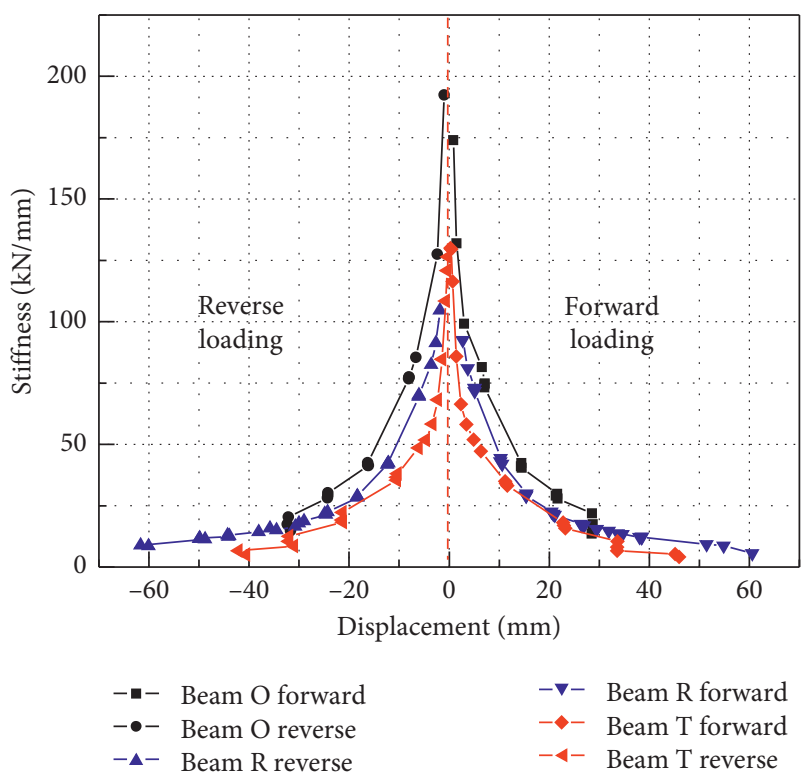

FIGURE 22: Stiffness degradation curves.

in the cyclic tests. The forward and reverse initial stiffnesses of beam $\mathrm{O}$ were larger than those of the other two beams. The stiffness of beam $\mathrm{T}$ was the smallest. As the loaded displacements increased, all the stiffnesses gradually degraded and approached each other. The stiffness of beam $\mathrm{O}$ decreased faster than the other two beams; the main reason for this phenomenon was that more concrete cracks initiated in the early stage.

The cyclic results suggested that for all three tests, the reinforcements yielded before the concrete was crushed, indicating that all the beams exhibited good ductility under earthquake effects. However, deploying openings on beams will impact the overall seismic performance, as indicated by the analysis above. Additional reinforcements around the openings will mitigate the impact to a certain degree. It is concluded that beams with openings can meet the seismic requirements in metro stations.

\section{Conclusion}

This paper conducted static and cyclic experiments to investigate the flexural behaviour of RC beams with different web openings used in an actual underground engineering project. Scaled beams were fabricated in the laboratory, and then static loading tests were conducted to investigate the effect of the web opening on the loadbearing capacity, total deformation, and strain distribution of the RC beams. Then, to explore the seismic behaviour of the beams under lowcycle repeated loads, the cyclic characteristics, such as hysteresis, energy dissipation capacity, ductility, and stiffness degradation, of the specimens were studied. The following conclusions were drawn from this study:

(a) In the static experiments, both beams $\mathrm{O}$ (one web opening) and $\mathrm{T}$ (three web openings) exhibited large deformation, apparent damage, and promising ductility. The obtained yield load for beam $\mathrm{O}$ was $328.9 \mathrm{kN}$, which was $65.9 \%$ larger than that for beam $\mathrm{T}(198.2 \mathrm{kN})$. Thus, the increment in the number of openings significantly decreased the loadbearing capacity of the beam, and even under the design loads, crack initiation and propagation occurred in the beams with openings.

(b) Under normal working conditions, the crack width near the openings was small and the stress in the longitudinal reinforcements was low; moreover, additional reinforcements around the openings can improve the loadbearing capacity of the beams with openings. Due to a torsional deformation of the openings and the stress concentrations induced by the sharp corners, the corners of the openings were shown to be the weakest parts of the beams with web openings. Therefore, special attention should be paid to strengthening the corners of web openings in engineering practice.

(c) In the cyclic experiments, the reference beam exhibited strong energy dissipation abilities. Moreover, the reverse sigmoidal hysteresis loops of beam $\mathrm{T}$ indicated that its energy dissipation abilities were greatly impacted by the openings. The envelope of the hysteresis curve of beam $\mathrm{O}$ was slightly narrower than that of the reference beam. However, the forward and reverse ultimate loads of beam O were 33\% and $23 \%$ larger than those of beam $\mathrm{R}$, respectively. Compared with beam $\mathrm{R}$, the displacement ductility coefficients of beam $\mathrm{O}$ and beam $\mathrm{T}$ were decreased by $18.1 \%$ and $37.6 \%$, respectively.

(d) Deploying openings on beams will impact the overall seismic performance, as indicated by the analysis above. Additional reinforcements around the openings will mitigate this impact to a certain degree. The beam with one opening achieved a good balance between seismic performance and providing essential services. 
The authors hope that the experimental tests conducted in this study together with future numerical analyses will facilitate the development of simple analytical models to predict the loadbearing capacity of underground metro station RC beams with various openings, which can be used as recommendations for engineers during routine designs.

\section{Data Availability}

The data used to support the findings of this study are included within the article.

\section{Conflicts of Interest}

The authors declare that there are no conflicts of interest regarding the publication of this paper.

\section{Acknowledgments}

The authors would like to acknowledge the support from the National Natural Science Foundation of China (grant nos. 51678248 and. 51878296); the Independent Research Program of the State Key Laboratory of Subtropical Building Science (grant no. 2017KB15), South China University of Technology; and the Open Research Fund of the State Key Laboratory of Simulation and Regulation of Water Cycles in River Basins (grant no. IWHR-SKL-KF201818).

\section{References}

[1] AIJ, Standard for Structural Calculation of Reinforced Concrete Structures-Based on Allowable Stress Concept-, Architectural Institute of Japan, Tokyo, Japan, 1999.

[2] ACI (American Concrete Institute), Building code requirements for structural concrete and commentary, American Concrete Institute, Farmington Hills, MI, USA, 2011.

[3] Canadian Standards Association, Design of Concrete Structures.Canadian Standards Association, Mississauga, Canada, 2004.

[4] A. F. Ashour and G. Rishi, "Tests of reinforced concrete continuous deep beams with web openings," ACI Structural Journal, vol. 97, no. 3, pp. 418-426, 2000.

[5] K. D. Tsavdaridis, C. D’Mello, and C. D’Mello, “Vierendeel bending study of perforated steel beams with various novel web opening shapes through nonlinear finite-element analyses," Journal of Structural Engineering, vol. 138, no. 10, pp. 1214-1230, 2012.

[6] G. Campione and G. Minafò, "Behaviour of concrete deep beams with openings and low shear span-to-depth ratio," Engineering Structures, vol. 41, pp. 294-306, 2012.

[7] B. Aykac, I. Kalkan, S. Aykac, and Y. E. Egriboz, "Flexural behavior of RC beams with regular square or circular web openings," Engineering Structures, vol. 56, pp. 2165-2174, 2013.

[8] A. R. Mohamed, M. S. Shoukry, and J. M. Saeed, "Prediction of the behavior of reinforced concrete deep beams with web openings using the finite element method," Alexandria Engineering Journal, vol. 53, no. 2, pp. 329-339, 2014.

[9] S. G. Morkhade and L. M. Gupta, "Experimental investigation for failure analysis of steel beams with web openings," Steel and Composite Structures, vol. 23, no. 6, pp. 647-656, 2017.
[10] S. G. Morkhade and L. M. Gupta, "Ultimate load behaviour of steel beams with web openings," Australian Journal of Structural Engineering, vol. 20, no. 2, pp. 124-133, 2019.

[11] S. G. Morkhade, M. Kshirsagar, R. Dange, and A. Patil, "Analytical study of effect of web opening on flexural behaviour of hybrid beams," Asian Journal of Civil Engineering, vol. 20, no. 4, pp. 537-547, 2019.

[12] S. G. Morkhade, S. M. Baswaraj, and C. B. Nayak, "Comparative study of effect of web openings on the strength capacities of steel beam with trapezoidally corrugated web," Asian Journal of Civil Engineering, vol. 20, no. 6, pp. 10891099, 2019.

[13] T. Almusallam, Y. Al-Salloum, H. Elsanadedy, A. Alshenawy, and R. Iqbal, "Behavior of FRP-strengthened RC beams with large rectangular web openings in flexure zones: experimental and numerical study," International Journal of Concrete Structures and Materials, vol. 12, no. 1, p. 47, 2018.

[14] X. F. Nie, S. S. Zhang, J. G. Teng, and G. M. Chen, "Experimental study on RC T-section beams with an FRPstrengthened web opening," Composite Structures, vol. 185, pp. 273-285, 2018.

[15] B. H. Osman, E. Wu, B. Ji, and S. S. Abdulhameed, "Repair of pre-cracked reinforced concrete (RC) Beams with openings strengthened using FRP sheets under sustained load," International Journal of Concrete Structures and Materials, vol. 11, no. 1, pp. 171-183, 2017.

[16] H. M. Elsanadedy, Y. A. Al-Salloum, T. H. Almusallam, A. O. Alshenawy, and H. Abbas, "Experimental and numerical study on FRP-upgraded RC beams with large rectangular web openings in shear zones," Construction and Building Materials, vol. 194, pp. 322-343, 2019.

[17] A. Arabzadeh and H. Karimizadeh, "Experimental study of RC deep beams with opening and FRP composites installed by means of EBR and EBROG methods," Construction and Building Materials, vol. 208, pp. 780-791, 2019.

[18] W. Zheng, D. Wang, and Y. Ju, "Performance of reinforced reactive powder concrete beam-column joints under cyclic loads," Advances in Civil Engineering, vol. 2018, Article ID 3914815, 12 pages, 2018.

[19] C.-C. Chen and T. Sudibyo, "Effect of intermediate stiffeners on the behaviors of partially concrete encased steel beams," Advances in Civil Engineering, vol. 2018, Article ID 8672357, 15 pages, 2018.

[20] Y. Li, H. Jiang, and T. Y. Yang, "Damage deformation of flexure-yielding steel-reinforced concrete coupling beams: experimental and numerical investigation," Advances in Civil Engineering, vol. 2019, Article ID 7071243, 15 pages, 2019.

[21] L. Herrera, S. Anacleto-Lupianez, and A. Lemnitzer, "Experimental performance of RC moment frame beams with rectangular openings," Engineering Structures, vol. 152, pp. 149-167, 2017.

[22] China Nonferrous Engineering Design Research, Handbook of Concrete Structure Construction, China Nonferrous Engineering Design Research, Beijing, China, 2016, in Chinese, 5th edition.

[23] C. V. R. Murty, R. K. Goel, A. Goyal et al., Reinforced Concrete Structure, Mir Publishers, Moscow, Russia, 1983. 